\title{
Anti-Leukemic Activity of Shikonin: Role of ERP57 in Shikonin Induced Apoptosis in Acute Myeloid Leukemia
}

\author{
Rachana Trivedia,b Gerhard A. Müller ${ }^{a}$ Manohar S. Rathore ${ }^{b}$ Durga P. Mishrab \\ Hassan Dihazi ${ }^{a}$ \\ ${ }^{a}$ Clinic for Nephrology and Rheumatology, University Medical Centre, Georg-August University,

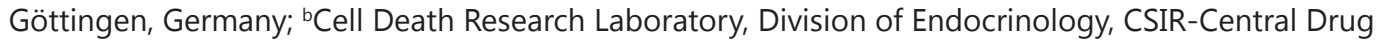 \\ Research Institute, Lucknow, India
}

\section{Key Words}

Acute Myeloid Leukemia • HL-60 • Shikonin • ERP57 • Apoptosis • ER-Stress

\begin{abstract}
Background/Aims: ER-Stress and activation of unfolded protein response belong to the major factors involved in chemoresistance in cancer cells. In this study we investigated the effect of shikonin on the survival of acute myeloid leukemia cells and the role of ER-stress protein ERP57, a protein disulfide isomerase, in improvement of chemotherapy. Methods: Using MTT assay we studied cytotoxic effects of shikonin on HL-60 cells. The flow cytometry was adopted to examine the shikonin induced mode of cell death in $\mathrm{HL}-60$ cells. The overall protein expression alteration resulting from shikonin treatment was investigated using proteomics methods. Western blotting was performed to quantify the alteration in protein expression in HL-60 after shikonin treatment. Silencing and overexpression studies were carried out to highlight the therapeutic role of ERP57 in shikonin effect on AML cells. Results: Shikonin induces apoptosis in HL-60 cells without significant effect on Primary cells from healthy volunteers. The apoptotic effect was dose and time dependent and was accompanied by strong alteration in cell proteome. Among the proteins targeted by shikonin, ERP57 was significantly downregulated in HL-60 after treatment. Compared to healthy control ERP57 was found to be highly expressed in AML cell line HL60 and was downregulated after shikonin treatment. Overexpression of ERP57 protected HL-60 from shikonin induced apoptosis, whereas knockdown of ERP57 expression resulted in increase in shikonin induced apoptosis. Conclusions: Our results demonstrate that ERP57 plays a crucial role in resistance towards shikonin induced apoptosis in AML cells. Targeting of ERP57 might offer a new therapeutic option for the treatment of acute myeloid leukemia.

\section{Introduction}

Acute myeloid leukemia (AML) is heterogeneous group of malignant disorder characterized at cellular level by an imbalance between cell proliferation and differentiation 


\section{Cellular Physiology Cell Physiol Biochem 2016;39:604-616

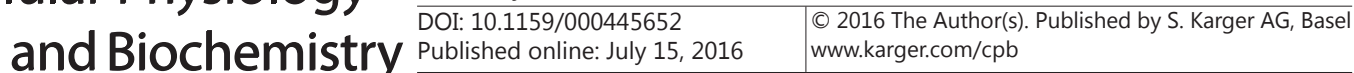 Trivedi et al.: ERP57 in AML Chemotherapy}

$[1,2]$. AML is still an incurable disease and innovative treatment strategies are urgently needed [3]. Unfolded protein response (UPR) is one of the factors playing an important role in chemoresistance in cancer cells $[4,5]$. UPR is an evolutionary conserved mechanism and is activated to compensate the adverse effects of protein accumulation in the endoplasmic reticulum (ER), following the induction of ER stress [6]. UPR induced activation of both proapoptotic and survival pathway allow eukaryotic cells to acclimatize to ER stress [7]. Protein folding is facilitated by different ER resident chaperones like the glucose regulated protein GRP78, calreticulin, calnexin and protein disulfide isomerases (PDI) [8]. ERP57 (PDIA3) is a member of protein disulfide isomerase and is also a glucose-regulated protein $[9,10]$. It plays a major role as a folding enzyme in quality control in the secretory pathway. In mammalian cells, the UPR consists of three transmembrane ER stress sensor proteinsprotein kinase RNA-like ER kinase (PERK), inositol-requiring kinase 1 (IRE1), and the activating transcription factor 6 (ATF6) [11]. These three molecules function as individual activators of transcriptional (IRE1, ATF6) and translational (PERK) programs. The UPR initiates transient attenuation of protein translation, degradation of misfolded proteins, and induction of molecular chaperones like calreticulin and GRP78 [12]. UPR is therefore cytoprotective and allow the cells to adapt to the environmental and developmental conditions that invade ER protein folding [13]. However, severe and prolonged ER stress may leads to apoptosis rather than being cytoprotective [14]. The collective activities of PERK, IRE1 and ATF6 leads to increased expression of effector stress response (XBP-1,ATF4and ATF6) and proapoptotic transcription factor (CHOP) additionally enhancing the expression of ER resident chaperones, such as GRP78 and GRP94 [4, 15].

Shikonin (C16H1605) is a naturally occurring naphthoquinone present in the root tissues of herb Lithospermum erythrorhizon. Shikonin shows pleiotropic effects including anti-tumor effect, accelerating tissue granulation proliferation, anti-ischemic, antiinflammatory, and anti-bacterial $[16,17]$. The antitumor activities of shikonin are mediated through its ability to down-regulate antiapoptotic proteins like Bcl-2 and Bcl-xL, oxidative stress and caspase activation [18-20]. Shikonin has also been reported to inhibit EGFR phosphorylation and cell cycle arrest through increased p53 expression [21, 22]. Shikonin also activates MAP kinases such as ERK2, JNK, and p38, which are implicated in the upstream regulation of apoptosis [23-25]. Due to its effective anticancer properties and circumventing drug resistance in cancer cells [26], we selected this compound for this study.

We demonstrate here that HL-60 and AML primary cells exhibit high level of ERP57, which was significantly downregulated after shikonin treatment. Shikonin also leads to downregulation of other ER stress protein markers from AML cell line to primary AML cells. Our results uncover the role of ERP57 in protection against shikonin induced apoptosis.

\section{Materials and Methods}

\section{Reagents}

RPMI-1640 was purchased from Gibco. L-glutamine, urea and DTT were from Sigma. Culture flasks were from Falcon, CHAPS [(3-Cholamidopropyl) dimethylammonio]-1-propanesulfonate] was from MERCK. Precision plus protein marker and Bio-LyteH were from Bio-Rad. BSA was from Roche. Colloidal Coomassie blue staining (Roti-Blue) was from Carl-Roth. Annexin V-fluorescein isothiocynate and propidium iodide were from Invitrogen. Ficoll, Tunicamycin and Bacitracin were purchased from Sigma-Aldrich.

\section{Cell culture and treatments}

The human myeloid cell line HL-60 was obtained from ATCC and culture were maintained in RPMI-1640 (Invitrogen, Karlsruhe, Germany) supplemented with 10\% fetal calf serum (Invitrogen) and $50 \mathrm{U} / \mathrm{mL}$ penicillin. The peripheral blood samples were obtained from normal healthy donors at UMG, Goettingen, Germany, after written informed consent in compliance with the Declaration of Helsinki 2002. Peripheral blood mononuclear cells (PBMCs) were separated by ficoll-hypaque density gradient $(1 \mathrm{~g} / \mathrm{ml})$ centrifugation method. Subsequently, the isolated cells $\left(10^{6} / \mathrm{ml}\right)$ were cultured in complete RPMI 1640 


\section{Cellular Physiology Cell Physiol Biochem 2016;39:604-616 \begin{tabular}{l|l} 
and Biochemistry Published online: July 15,2016 & $\begin{array}{l}\text { C } 2016 \text { The Author(s). Published by S. Karger AG, Basel } \\
\text { www.karger.com/cpb }\end{array}$ \\
\hline
\end{tabular} \\ Trivedi et al.: ERP57 in AML Chemotherapy}

medium supplemented with $10 \%$ FBS.

Shikonin was obtained from Calbiochem. $10 \mathrm{mM}$ stock solution was prepared in DMSO. For sequential treatments, cells were treated for $24 \mathrm{~h}, 48 \mathrm{~h}$ and $72 \mathrm{~h}$ with increasing doses of shikonin. To study the ERstress induced apoptosis, cells were pretreated with $10 \mu \mathrm{g} / \mathrm{ml}$ tunicamycin for $6 \mathrm{~h}$ before $2.5 \mu \mathrm{M}$ shikonin treatment for further $24 \mathrm{~h}$. Further, to study the role of ERP57 in protection of shikonin induced apoptosis, HL-60 cells were pretreated with $300 \mu \mathrm{M}$ Bacitracin for $6 \mathrm{~h}$ before $2.5 \mu \mathrm{M}$ shikonin treatments for next $24 \mathrm{~h}$.

Measurement of cell viability

$6 \times 10^{3}$ cells/well was seeded in 96-well plated and treated with different doses of shikonin for 24 h, $48 \mathrm{~h}$ and $72 \mathrm{~h}$. Cell viability was assessed using cell Proliferation Kit I (MTT), a colorimetric assay for the non-radioactive quantification of cell proliferation and viability (Roche Applied Bioscience, Mannheim, Germany).

\section{Analysis of Apoptosis by flow cytometry}

To determine apoptosis rate, cells were stained with Annexin/PI after $24 \mathrm{~h}$ of shikonin treatment. Samples were incubated at $37^{\circ} \mathrm{C}$ for 15 minutes and analysed on a Becton Dikinsion FACS Calibur.

\section{Western Blot analysis}

Whole cell protein extracts were obtained from HL-60 cells. $50 \mu \mathrm{g}$ cell extracts were run on $12 \%$ SDS PAGE after denaturation with Laemmli buffer subsequently western blot analysis was performed as described previously [27]. Antibodies against mouse ERP57 (Enzo lifesciences), rabbit GRP78 (sigma), goat calreticulin (Abcam), rabbit IRE1A(Cell Signalling Technology), rabbit GRP94 (Sigma), mouse cleaved ATF6 (Acris Antibodies)and mouse beta actin (Sigma) were used as primary antibodies, diluted in blocking buffer, then added to the membrane and incubated at $4^{\circ} \mathrm{C}$ for overnight. Molecular probes AlexaFlour 647 goat anti-mouse IgG antibody or AlexaFlour 647 goat anti-rabbit IgG antibody or AlexaFlour 647 donkey antigoat IgG antibody were used as secondary antibody. Before imaging, the blots were dried in the dark. The blot membranes were scanned at a resolution of $50 \mu \mathrm{m}$ on a Fuji FLA-5100 scanner (Fuji Photo, Kanagawa, Japan) with single laser-emitting excitation light at $635 \mathrm{~nm}$ and $670 \mathrm{~nm}$, respectively.

\section{2-D gel electrophoresis}

2-D gel electrophoresis was performed as described previously [28]. For protein identification, 2-DE gels were additionally stained with colloidal Coomassie blue, Roti-Blue (Roth, Karlsruhe, Germany) overnight. Cells were washed with PBS and the resulting pellet was solubilized in lysis buffer ( $9.5 \mathrm{M}$ urea, $2 \% \mathrm{w} / \mathrm{v}$ CHAPS, $2 \% \mathrm{v} / \mathrm{v}$ ampholytes, and $1 \% \mathrm{w} / \mathrm{v}$ DTT) at $4{ }^{\circ} \mathrm{C}$ for $30 \mathrm{~min}$, centrifuged ( $\left.5 \mathrm{~min}, 13,000 \mathrm{~g}\right)$, and the protein concentration of the supernatant was determined as described above. The Fluorescent images were captured in16-bit TIFF files format. Spot matching across gels and normalization based on the internal standard was performed using Delta2D software (Decodon, Greifswald, Germany). For protein identification, 2-DE gels were post-stained with colloidal Coomassie blue (Roti-Blue) overnight. Differentially regulated proteins were excised and processed for identification by MS.

Protein identification from 2-DE gels

In-gel digestion and peptide extraction were carried out as described previously [28]. Subsequently the extracted peptides were subjected to peptide sequence analysis. The samples were dissolved in $0.1 \%$ formic acid and processed as described previously [28]. Processed data were searched against MSDB and Swissprot databases through the Mascot search engine using a peptide mass tolerance of 50 ppm (parts per million) and fragment tolerance of $100 \mathrm{mmu}$ (millimass unit). Protein identifications with at least two peptides sequenced were considered significant.

\section{Transfection}

For siRNA-mediated gene knockdown, 4 x 106 cells were transfected with siRNA oligonucleotide specific for the knockdown of ERP57 expression (Sense Strand: 5' ACC TCG TCC TTC ACA TCT CAC TAA CAT CAA GAG TGT TAG TGA GAT GTG AAG GACTT 3'), (Antisensestrand:3' CAA AAA GTC CTT CAC ATC TCA CTA ACA CTC TTG ATG TTA GTG AGA TGT GAA GGACG-5') were designed in our laboratory and synthesized by Eurofins MWG Operon (Germany)as control for knock-down efficiency Non Specific Controls from Eurofins 


\begin{tabular}{|c|c|c|}
\hline \multirow{2}{*}{$\begin{array}{c}\text { Cellular Physiology } \\
\text { and Biochemistrv }\end{array}$} & \multicolumn{2}{|c|}{ Cell Physiol Biochem 2016;39:604-616 } \\
\hline & $\begin{array}{l}\text { DOI: 10.1159/000445652 } \\
\text { Published ollin: July } 15,2016\end{array}$ & $\begin{array}{l}\text { O } 2016 \text { The Author(s). Published by S. Karger AG, Basel } \\
\text { www.karger.com/cpb }\end{array}$ \\
\hline
\end{tabular}

MWG were used. HL-60 cells with 70\% confluence were transfected with the siRNA ERP57 using transfection reagent, Lipofectamine 2000 (Invitrogen) according to the manufacturer's protocol. Transfection reagent was removed after $6 \mathrm{~h}$ replaced with normal complete culture medium.

For the overexpression of ERP57, 70\% confluent HL-60 cells were transfected either with pcDNA3.1ERP57 (a gift from Dr. Neil Bulleid University of Glasgow) or empty pcDNA3.1using transfection reagent, LTX reagent with PLUS reagent (Invitrogen) according to the manufacturer's protocol. After $6 \mathrm{~h}$ of transfection media was replaced with normal complete media supplemented with $0.5 \mathrm{mg} / \mathrm{ml} \mathrm{G-418} \mathrm{(Invitrogen)} \mathrm{as} \mathrm{a}$ selection factor for stable transfection.

Both overexpression and knockdown of ERP57 was confirmed by performing western blotting.

\section{Statistical Analysis}

All the values are represented as mean \pm SEM from at least three independent experiments. Data was analyzed using One-way ANOVA followed by Newman Keuls comparison test. Values with $* \mathrm{P}<0.05$ was considered to be significant. For 2-DE the digitalized images were analyzed; spot matching across gels and normalization were performed using Delta2D 3.4 (Decodon, Braunschweig, Germany). Delta2D computes a 'spot quality' value for every spot detected. This value shows how closely a spot represents the 'ideal' 3D Gaussian bell shape. On the basis of the average spot volume ratio, spots whose relative expression is changed at least two fold (increase or decrease) between the compared samples were considered to be significant. To analyze the significance of protein regulation, Student's t-test was performed, and statistical significance was assumed for $* \mathrm{P}<0.05$. All blots were quantified using the ImageJ software. For comparison between two measures (in the same group) the paired t-test was used.

\section{Results}

Shikonin displays potent antileukemic activity

To test the antiproliferative/cytotoxic effect of shikonin (Fig. 1A) against HL-60 (Fig. 1B) and blood cells derived from normal volunteer (Fig. 1C) were treated with increasing doses of shikonin $(0.5-10 \mu \mathrm{M})$ for $24 \mathrm{~h}, 48 \mathrm{~h}$ and $72 \mathrm{~h}$, and the cell viability was analysed by MTT assay. Shikonin showed significant antileukemic activity in HL-60 cells, with IC50 values $3.83 \mu \mathrm{M}$ at $48 \mathrm{~h}$. Shikonin showed no cytotoxic effect against primary cells isolated from healthy donors. Our MTT results clearly showed that shikonin has efficient antileukemic activity without significant effect on normal cells.

Shikonin induces apoptosis in AML cells

To address the question of mode of cell death induced by shikonin, we first examined the morphological features of HL-60 during shikonin treatment using phase contrast light microscopy

Fig. 1. Shikonin inhibits the proliferation of HL-60 cells and Primary AML cells. (A) Structure of shikonin. HL-60 cells and Primary cells from healthy volunteers were treated with indicated doses of shikonin for 24,48 and $72 \mathrm{~h}$ (BC). Cell viability was measured using Cell Proliferation Kit I (MTT) (Roche Applied Bioscience, Mannheim, Germany).

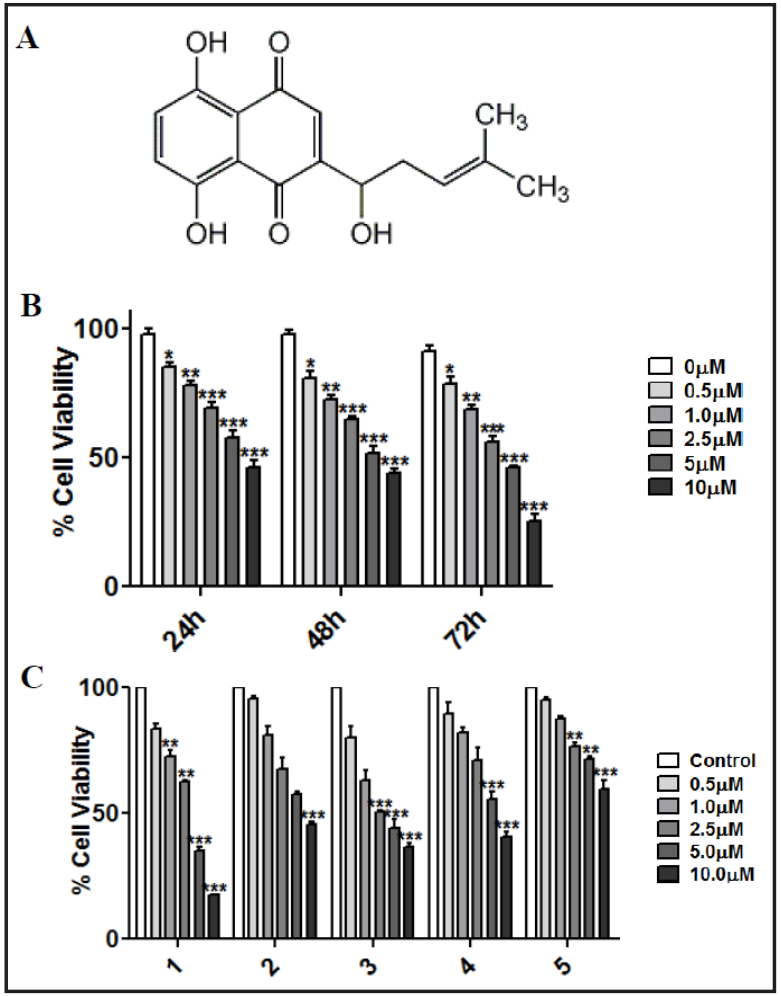




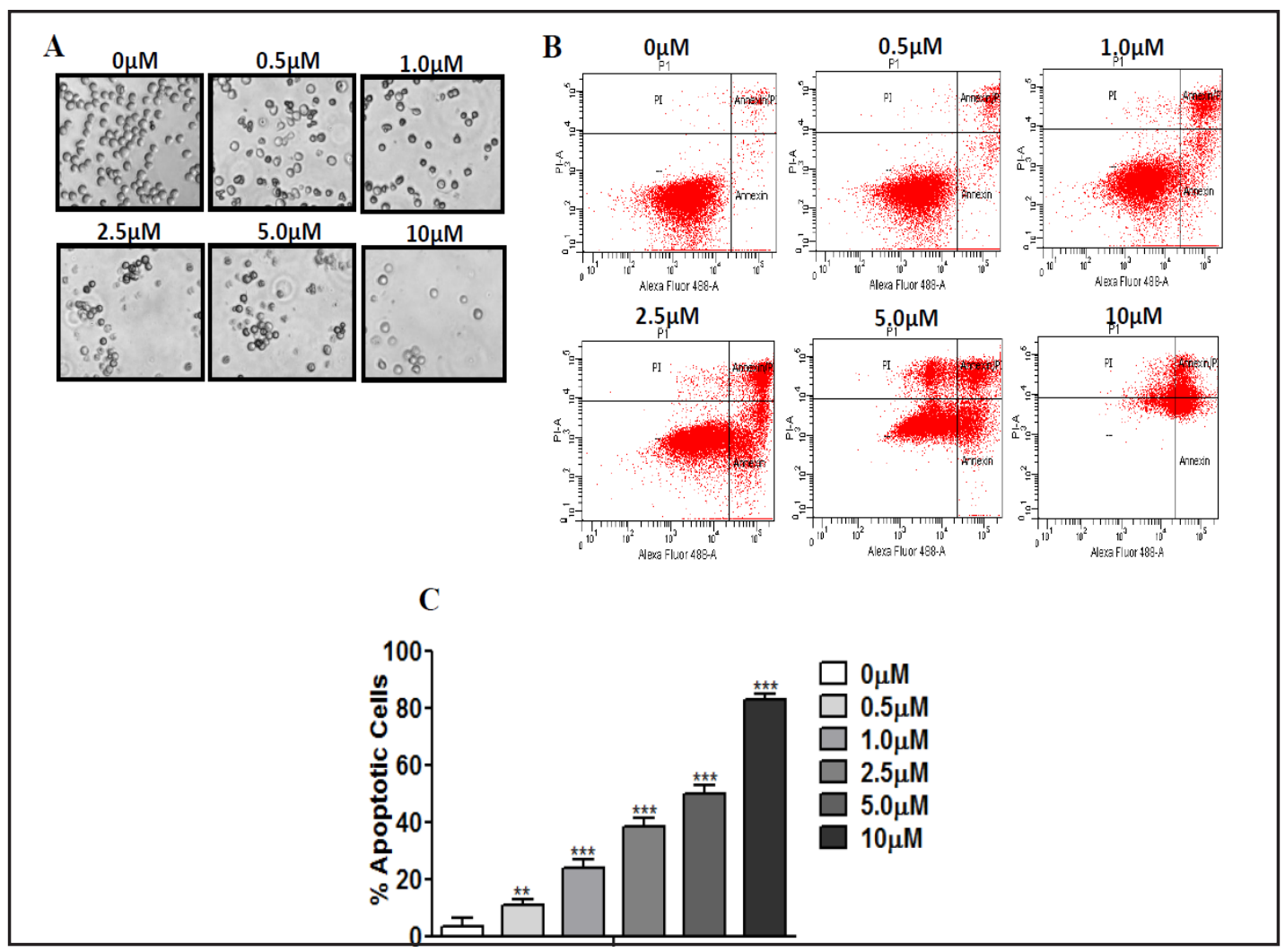

Fig. 2. Shikonin induces apoptosis in HL-60 cells. (A) Shikonin induced morphological changes were observed in HL-60 cells. HL-60 cells were treated with indicated doses of shikonin for $24 \mathrm{~h}$ and morphological changes were observed under the phase contrast microscope. (B) HL-60 cells were treated with increasing doses of shikonin for $24 \mathrm{~h}$ and Annexin-V/PI staining was performed to examine the apoptotic cells. (C) Percentage of apoptotic cells after treatment with indicated doses of shikonin for $24 \mathrm{~h}$.

Fig. 3. Shikonin induced change in proteome of HL-60 cells. (A) HL-60 cells were treated with $2.5 \mu \mathrm{M}$ shikonin for $24 \mathrm{~h}$ and 2D gel electrophoresis was performed. Overlay of 2D-gels of samples from shikonin treated HL-60 cells (Orange) compared to HL-60 cell control (Blue).The identified proteins are indicated with gene names. (B) Classification of differentially expressed proteins upon shikonin treatment according to their biological process.

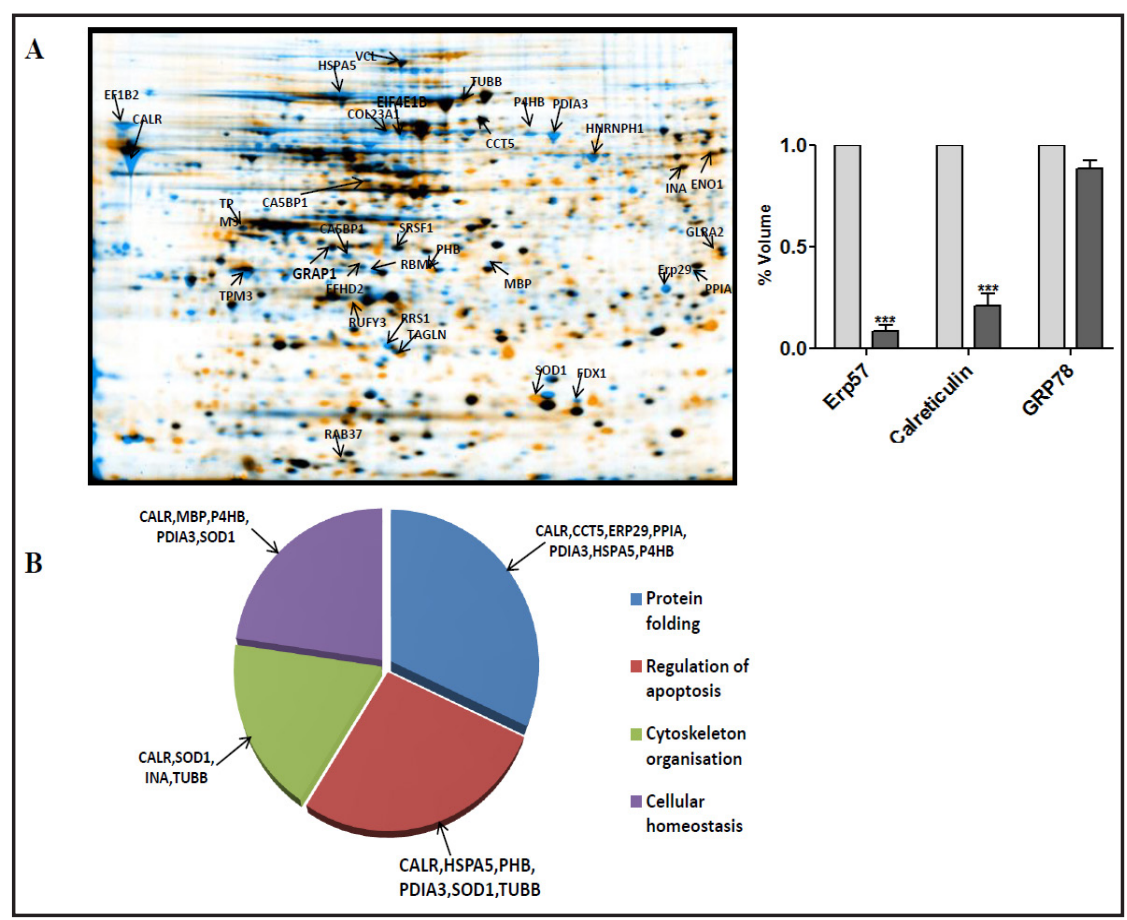




\begin{tabular}{|c|c|c|}
\hline \multirow{2}{*}{$\begin{array}{c}\text { Cellular Physiology } \\
\text { and Biochemistry }\end{array}$} & \multicolumn{2}{|c|}{ Cell Physiol Biochem 2016;39:604-616 } \\
\hline & $\begin{array}{l}\text { Dol: 10.1159/000445652 } \\
\text { Published ollin: }\end{array}$ & $\begin{array}{l}02016 \text { The Author(s). Published by S. Karger AG, Basel } \\
\text { wwwwkargercom/cpb }\end{array}$ \\
\hline
\end{tabular}

Table 1. List of proteins found to be regulated under shikonin treatment in HL-60 cells. Listed are the gene and proteins names of non-redundant proteins, nominal mass of the proteins, calculated isoelectric point, and the MS/MS Score

\begin{tabular}{|c|c|c|c|c|c|}
\hline Protein name & $\begin{array}{l}\text { Gene } \\
\text { name }\end{array}$ & Swiss-prot & $\begin{array}{l}\text { Nominal } \\
\text { mass }\end{array}$ & CPI & $\begin{array}{l}\text { MS/MS- } \\
\text { Score }\end{array}$ \\
\hline Superoxide Dismutase Cu-Zn & SOD1 & SODC_HUMAN & 16154 & 5.7 & 58 \\
\hline Tropomycin alpha-3 & TPM3 & TMP3_HUMAN & 32987 & 4.68 & 99 \\
\hline Alpha Enolase & ENO1 & ENOA_HUMAN & 47481 & 7.01 & 118 \\
\hline Vinculin & VCL & VINC_HUMAN & 124292 & 5.5 & 84 \\
\hline GRP78 & HSPA5 & GRP78_HUMAN & 72402 & 5.07 & 79 \\
\hline Protein disulfide -isomerase & P4HB & PDIA1_HUMAN & 57480 & 4.76 & 194 \\
\hline Tubulin beta chain & TUBB & TBB5_HUMAN & 50095 & 4.78 & 78 \\
\hline Serine/Arginin-rich splicing factor 1 & SRSF1 & SRSF1_HUMAN & 27842 & 10.37 & 97 \\
\hline EF-Hand domain-containing protein D2 & EFHD2 & EFHD2_HUMAN & 267.95 & 5.15 & 80 \\
\hline Endoplasmic reticulam resident protein 29 & ERP29 & ERP29_HUMAN & 29032 & 6.77 & 84 \\
\hline Tropomycin alpha-3 & TPM3 & TMP3_HUMAN & 32987 & 4.68 & 61 \\
\hline Protein disulfide -isomerase A3 & PDIA3 & PDIA3_HUMAN & 57146 & 5.98 & 203 \\
\hline Calreticulin & CALR & CALR_HUMAN & 48255 & 4.29 & 95 \\
\hline Prohibitin & PHB & PHB_HUMAN & 29843 & 5.57 & 98 \\
\hline $\begin{array}{l}\text { Eukaryotic translation initiation factor } 4 \mathrm{E} \\
\text { type } 1 \mathrm{~B}\end{array}$ & EIF4E1B & I4E1B_Human & 27750 & 6.68 & 167 \\
\hline Collagen alpha- 1 chain & COL23A1 & CONA1_HUMAN & 52254 & 6.88 & 230 \\
\hline Myelin basic protein & MBP & MBP_HUMAN & 33097 & 9.79 & 135 \\
\hline Protein RUFY3 & RUFY3 & RUFY3_HUMAN & 53216 & 5.36 & 237 \\
\hline Glycin receptor subunit alpha-2 & GLRA2 & GLRA2_HUMAN & 52425 & 9.06 & 142 \\
\hline Transgelin & TAGLN & TAGLN_HUMAN & 22653 & 8.87 & 124 \\
\hline Elongation factor 1-beta & EF1B2 & EF1B_HUMAN & 24919 & 4.5 & 227 \\
\hline Zinc-finger protein 442 & ZNF44.2 & ZN44_HUMAN2 & 75325 & 9.03 & 312 \\
\hline Tropomycin beta chain & TPM2 & TMP2_HUMAN & 32987 & 4.68 & 174 \\
\hline GRIP1-associated protein 1 & GRAP1 & GRAP1_HUMAN & 96273 & 5.08 & 140 \\
\hline Ras-related protein Rab-37 & RAB37 & RAB_HUMAN & 25028 & 5.97 & 230 \\
\hline $\begin{array}{l}\text { Putative inactive carbonic anhydrase 5B-like } \\
\text { protein }\end{array}$ & CA5BP1 & CA5BL_HUMAN & 22779 & 10.76 & 89 \\
\hline RNA-binding motif protein,x chromosome & RBMX & RBMX_HUMAN & 42306 & 10.06 & 79 \\
\hline Adrenodoxin,mitochondrial & FDX1 & ADX-HUMAN & 19666 & 4.9 & 106 \\
\hline T-complex protein 1 subunit epsilon & CCT5 & TCPE_HUMAN & 60089 & 5.45 & 87 \\
\hline Mettalothionein-1E & MT1 & MT1E_HUMAN & 7150 & 8.38 & 94 \\
\hline $\begin{array}{l}\text { Dexamethasone-induced ras related protein } \\
1\end{array}$ & RASD1 & RASD1_HUMAN & 32021 & 9.15 & 97 \\
\hline Tubulin beta chain & TUBB & TBB5_HUMAN & 50095 & 4.78 & 72 \\
\hline Heterogenous nuclear ribonucleoprotein & HNRNPH1 & HNRH1_HUMAN & 49484 & 5.89 & 150 \\
\hline Peptidyl - prolyl cis-trans isomerase A & PPIA & PPIA_HUMAN & 18229 & 7.68 & 140 \\
\hline Alpha-internexin & INA & AINX_HUMAN & 55528 & 5.34 & 75 \\
\hline $\begin{array}{l}\text { Putative inactive carbonic anhydrase 5B-like } \\
\text { protein }\end{array}$ & CA5BP1 & CA5BL_HUMAN & 22779 & 10.76 & 86 \\
\hline $\begin{array}{l}\text { Ribosome biogenesis regulatory protein } \\
\text { homolog }\end{array}$ & RRS1 & RRS1_HUMAN & 41225 & 10.69 & 92 \\
\hline
\end{tabular}

(Fig. 2A). HL-60 cells were treated with various doses of shikonin for $24 \mathrm{~h}$ and apoptosis was detected by Annexin V/PI staining. In HL-60 cells, a dose dependent increase in the population of apoptotic cells was observed (Fig. 2B, C). Similar effect was also observed in U937 cell line treated with shikonin (data not shown).

\section{Investigation of the effect of shikonin treatment on HL-60 proteome}

To assess global protein expression changes and targeted protein pathways upon shikonin treatment, we applied 2-DE-based proteomics approach. Protein lysates from shikonin-treated and -untreated cells were separated first by IEF followed by SDS-PAGE separation. Protein expression patterns from the two cell extracts were compared with each other using the Delta2D 4.3 software (Decodon $\mathrm{GmbH}$ ). Two-dimensional protein maps derived from the cell extracts were analyzed with
Table 2. List of proteins which were significantly downregulated after shikonin treatment

\begin{tabular}{lc}
\hline Gene Name & $\begin{array}{c}\text { Spot volume Rati } \\
\text { Treated/Control }\end{array}$ \\
\hline TPM3 & 0.279 \\
VCL & 0.137 \\
P4HB & 0.399 \\
SRSF1 & 0.508 \\
ERP29 & 0.158 \\
PDIA3 & 0.085 \\
EIF4E1B & 0.36 \\
MBP & 0.332 \\
TMP2 & 0.279 \\
CA5BP1 & 0.168 \\
RBMX & 0.452 \\
HNRNPH1 & 0.226 \\
PPIA & 0.550 \\
RRS1 & 0.550 \\
CALR & 0.213 \\
\hline
\end{tabular}




\section{Cellular Physiology Cell Physiol Biochem 2016;39:604-616 \begin{tabular}{l|l} 
DOI: 10.1159/000445652 & $\begin{array}{l}\text { O 2016 The Author(s). Published by S. Karger AG, Basel } \\
\text { www.karger.com/cpb }\end{array}$
\end{tabular} Trivedi et al.: ERP57 in AML Chemotherapy}

conventional 2- DE in the $\mathrm{pH}$ ranges 4-7 and in total, 37 protein spots were found to be regulated when comparing the spot volumes. The proteins were successfully identified with highly significant MOWSE score (Table 1). Among these proteins 15 were identified as significantly downregulated (Table 2), whereas 7 were found to be significantly upregulated (Table 3). The identified proteins were found to be associated with different biological functions and a large number of them could be classified into four functional categories (Fig. 3B) (Table 4): the first category grouped the proteins that are known to be involved in ER stress and protein folding (CALR, CCT5, ERP29, PPIA, PDIA3, HSPA5, and P4HB), confirming role of protein folding proteins in AML cell survival. The other three categories involved regulation of apoptosis (CALR, HSPA5, PHB PDIA3, SOD1 and TUBB), cytoskeleton organization (CALR, SOD1, INA and TUBB), and cellular homeostasis (CALR, MBP, P4HB, PDIA3 and SOD1). Similar to Mitoxantrone effect [29], ERP57 downregulation was also observed in HL-60 after shikonin treatment. As shown in proteomic data, Fig. 3A, shikonin treatment induces significant downregulation of ERP57 and calreticulin (CALR) after $24 \mathrm{~h}$ of incubation.
Table 3. List of proteins which were significantly upregulated after shikonin treatment

\begin{tabular}{lc}
\hline Gene name & Spot volume Ratio Treated/Control \\
& \\
\hline EN01 & 5.834 \\
RUFY3 & 5.805 \\
GLRA2 & 11.027 \\
TAGLN & 2.693 \\
EF1B2 & 1.952 \\
INA & 1.960 \\
CA5BP1 & 1.979 \\
\hline
\end{tabular}

Table 4. Gene ontology functional annotation of proteins, which were regulated in this experiment according to their involvement in different biological processes

\begin{tabular}{|c|c|c|c|}
\hline Biological process & Proteins & Shk>C & $\mathrm{C}>\mathrm{Shk}$ \\
\hline Protein folding & 7 & CCT5 & $\begin{array}{l}\text { CALR } \\
\text { ERP29 } \\
\text { PPIA } \\
\text { PDIA3 } \\
\text { P4HB } \\
\text { HSPA5 }\end{array}$ \\
\hline Regulation of apoptosis & 6 & $\begin{array}{l}\text { PHB } \\
\text { SOD1 } \\
\text { TUBB }\end{array}$ & $\begin{array}{l}\text { CALR } \\
\text { HSPA5 } \\
\text { PDIA3 }\end{array}$ \\
\hline Cytoskeleton organisation & 4 & $\begin{array}{l}\text { SOD1 } \\
\text { TUBB } \\
\text { INA }\end{array}$ & CALR \\
\hline Cellular homeostasis & 5 & SOD1 & $\begin{array}{l}\text { CALR } \\
\text { P4HB } \\
\text { PDIA3 } \\
\text { MBP }\end{array}$ \\
\hline
\end{tabular}

Shikonin treatment reduces the ER-stress in AML

To validate the downregulation of ER-stress marker proteins result obtained from proteomics data, we performed western blot analysis in untreated and shikonin treated HL-60 cells. We found that ER-stress marker proteins were downregulated after shikonin treatment. Interestingly ERP57 and CALR were significantly downregulated in HL-60 cells after shikonin treatment both in dose (Fig. 4A) and time dependent (Fig. 4B) manner confirming the result obtained from proteomic data.

To further study the role of ERP57 in AML development, we performed western blotting in blood cells derived from healthy donors. The data showed clearly that healthy donors express very low amount of ERp57 and CALR (Fig. 4C). Further validation of overexpression of ERp57 in AML patients is required to confirm this result with AML primary cells.

\section{ER-stress inducer Tunicamycin diminishes the shikonin induced apoptosis}

To further study the role of ER-stress in AML cell progression, we pretreated HL-60 cells with Tunicamycin prior to shikonin treatment. The data clearly demonstrate that Tunicamycin reduced the shikonin induced apoptosis (Fig. 5A). Thus, we conclude that ER-stress is a key factor in developing resistance in AML cells against shikonin. As previous study has shown that inhibition of protein disulfide isomerase (PDI) activity increases apoptosis in response to ER-stress inducers [30], we further investigated the effect of PDIs inhibitor bacitracin on shikonin induced apoptosis. And we found that bacitracin increases shikonin induced 
$\mathbf{A}$

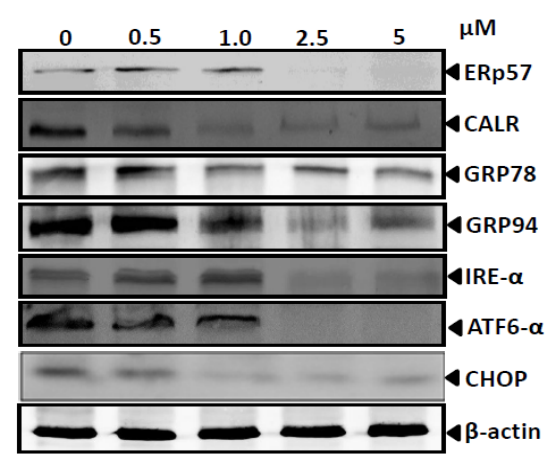

B

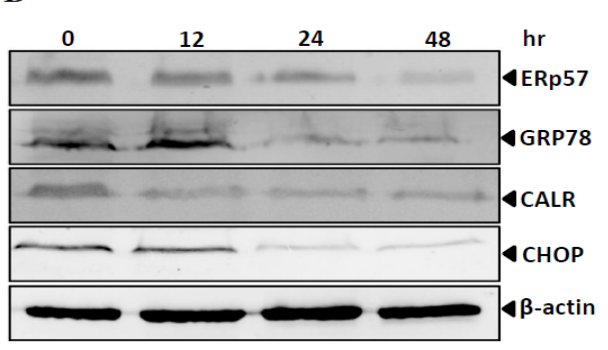

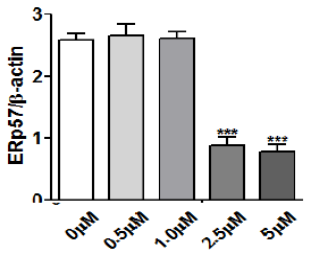
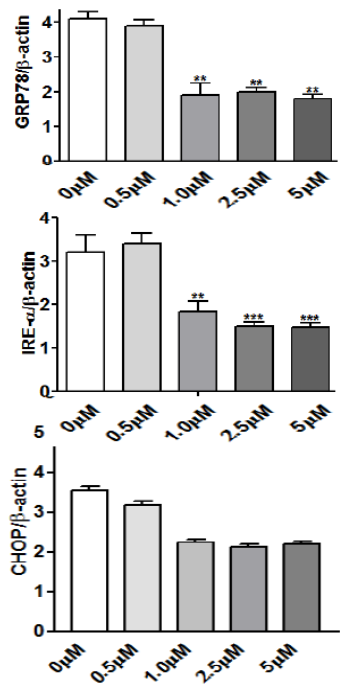
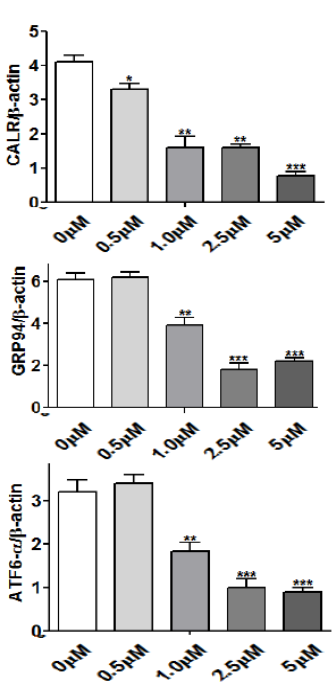
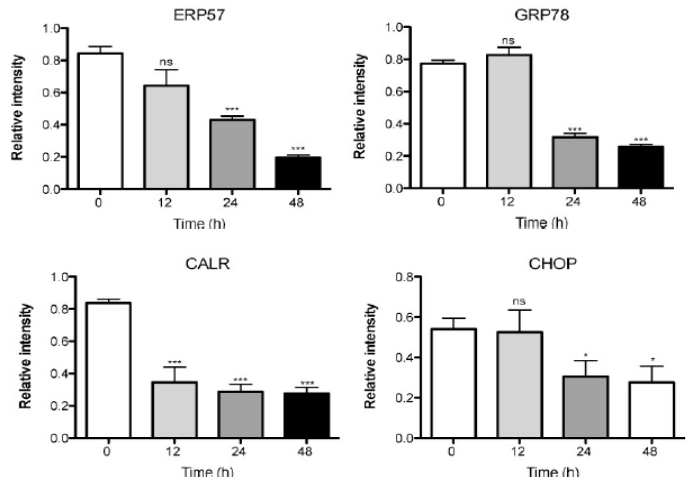

C
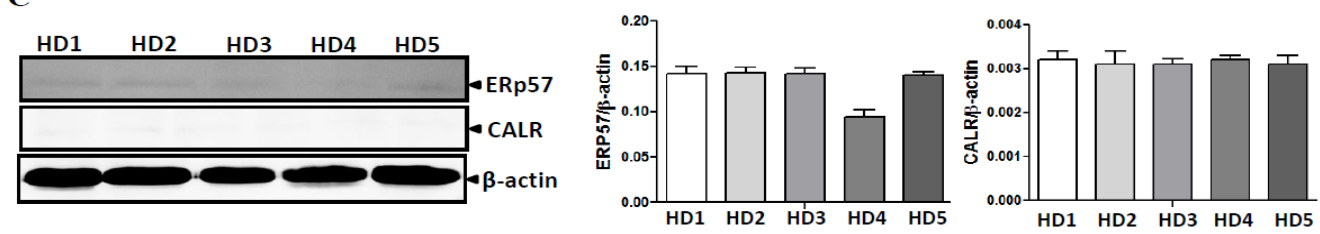

Fig. 4. Shikonin reduces ER-stress in HL-60 cells. (A) HL-60 cells were treated with indicated doses of shikonin for $24 \mathrm{~h}$ and then analyzed by western blotting. (B) HL-60 cells were treated for different time with shikonin and the expression regulation of ER-stress proteins and CHOP were monitored using western blot (C) Cell lysate were prepared from PBMCs derived from healthy volunteers to study the expression of ERP57 and CALR in healthy donors. Bar charts representing the quantification of the blots. Results are given as the means $\pm \mathrm{SD}$ from four independent experiments. ${ }^{*} \mathrm{P}<0.05,{ }^{* *} \mathrm{P}<0.01,{ }^{* * *} \mathrm{P}<0.001$.

apoptosis confirming the role of PDIs in protection against shikonin induced apoptosis (Fig. $5 \mathrm{~A})$.

As the inhibition of PDIs clearly improve the effect of shikonin, and our proteomic data showed that among the PDIs, ERP57 was targeted by shikonin; we investigated the change 


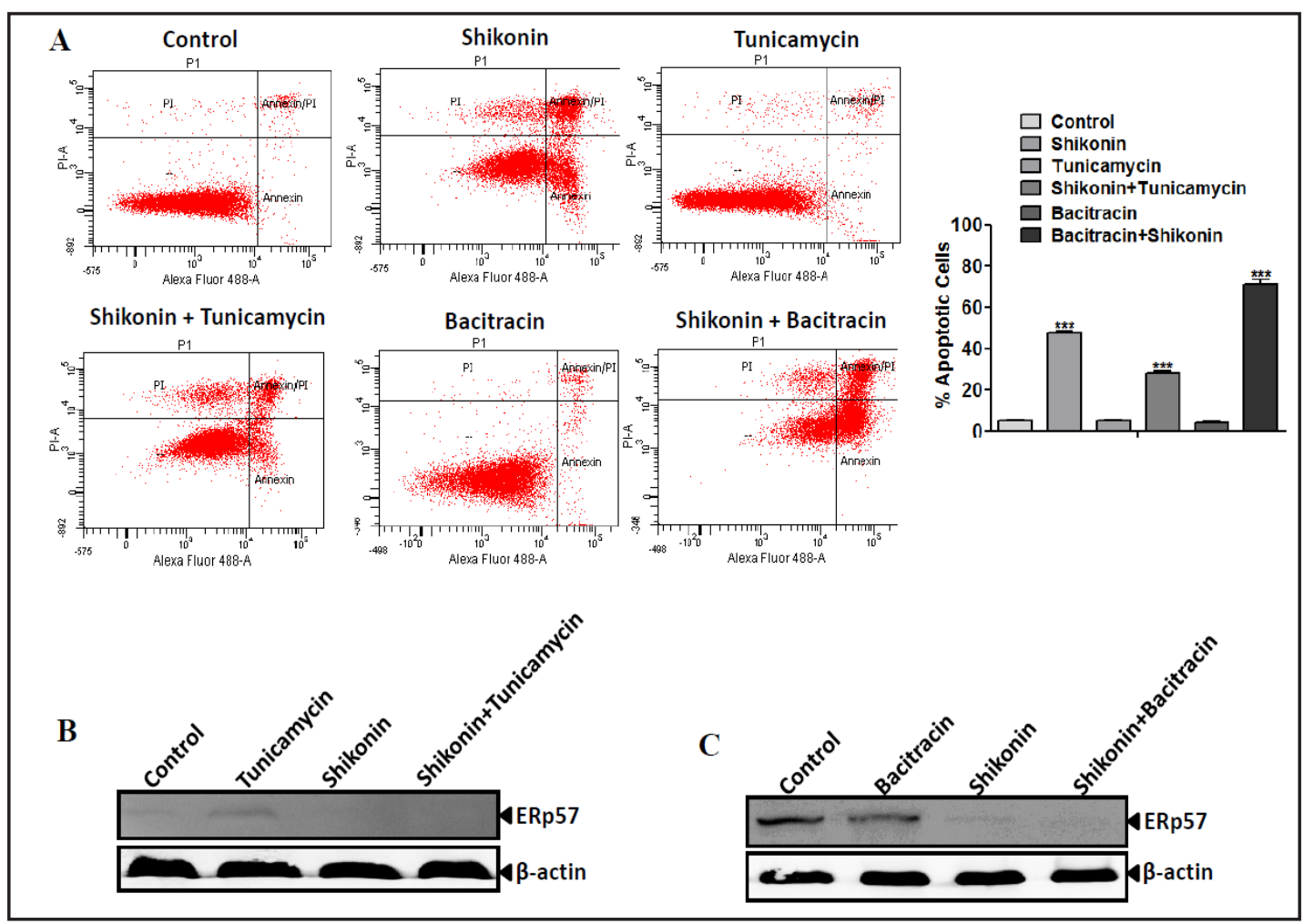

Fig. 5. Tunicamycin diminishes Shikonin induced apoptosis in HL-60 cells. (A) HL-60 cells were pretreated with Tunicamycin or Bacitracin alone $1 \mathrm{~h}$ before shikonin treatment and Annexin-V/PI staining was performed to study the role of ER-stress and ERP57 in shikonin induced apoptosis. Percentage of apoptotic cells after pretreatment with Tunicamycin and Bacitracin for $1 \mathrm{~h}$ before shikonin treatment. (B) HL-60 cells were pretreated with Tunicamycin or Bacitracin alone $1 \mathrm{~h}$ before shikonin treatment and cell lysate were prepared to perform the western blotting.

in expression of ERP57 after combination treatment of shikonin and tunicamycin and our results clearly showed that tunicamycin increased expression of ERP57, was significantly inhibited by shikonin treatment (Fig. 5B). On another way, combination of shikonin and bacitracin resulted in significant down regulation of ERP57 in HL-60 cells (Fig. 5C).

Thus, our results demonstrates that shikonin induced apoptosis is accompanied by downregulation of ERP57. Furthermore tunicamycin mediated up-regulation of ERP57 was inhibited by shikonin. Taken this together the data suggest that ERP57 is a key protein in response to shikonin induced apoptosis in AML cells.

\section{ERp57 is a key player in AML cell response to shikonin treatment}

To further study the crucial role of ERP57 in shikonin induced apoptosis; HL-60 cells were transfected prior to shikonin treatment with ERP57 siRNA and pcDNA3.1-ERP57 for knockdown and overexpression of ERP57 respectively (Fig. 6A). Furthermore, knockdown of ERP57 expression resulted in increase in apoptosis in HL-60 (Fig. 6B) cells and in and U937 cells (data not shown) treated with shikonin, whereas overexpression of ERP57 resulted in decrease in apoptosis (Fig. 6B). Hence our results suggest that ERP57 is the key player in AML cells response to shikonin treatment.

\section{Discussion}

Acute Myeloid Leukemia (AML) is a disastrous haematological malignancy characterized by the rapid growth of abnormal white blood cells [31]. In spite of recent improvement in

\section{KARGER}




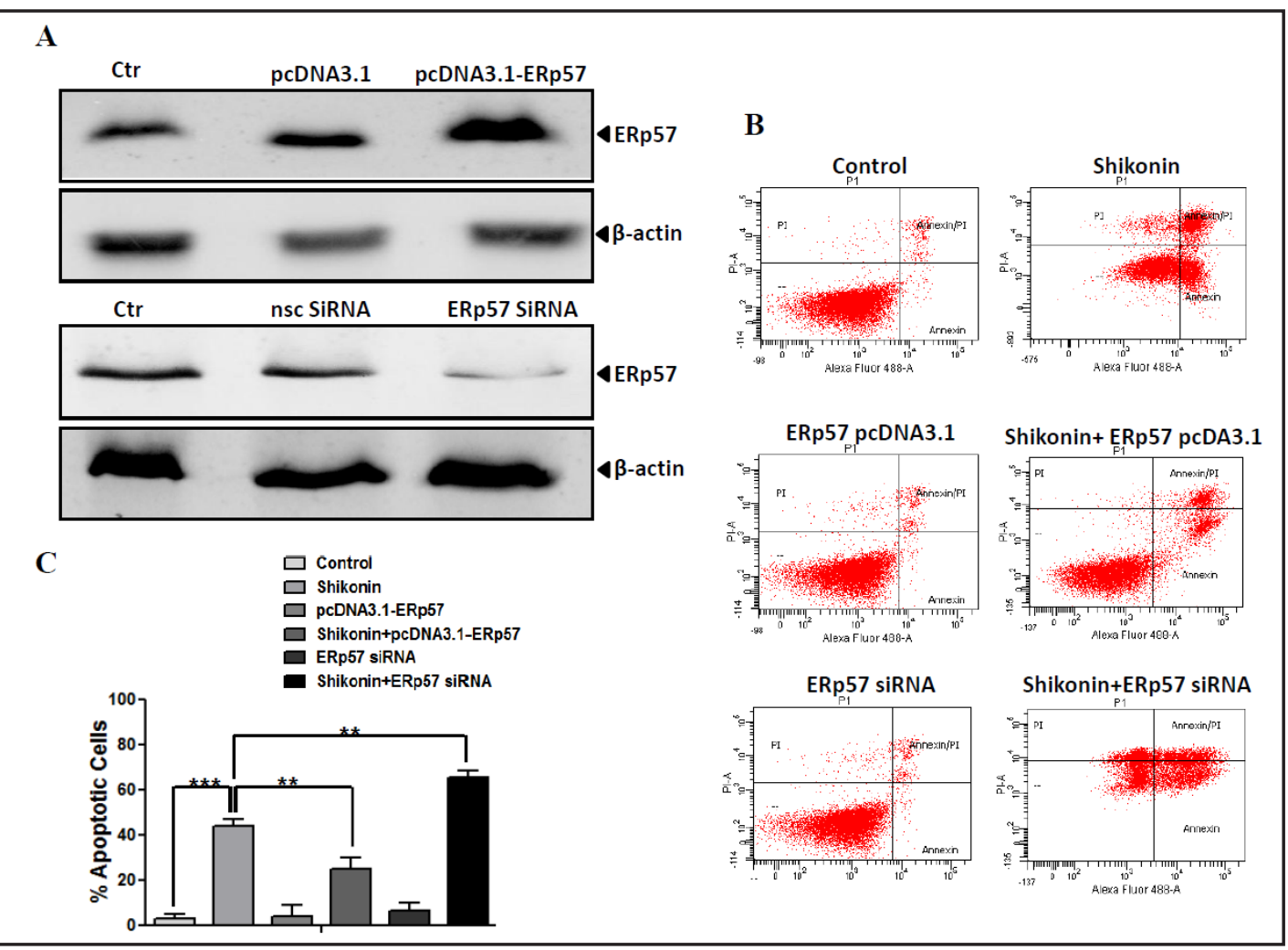

Fig. 6. ERP57 downregulation is the key mediator of Shikonin induced apoptosis. (A) HL-60 cells were transfected with pcDNA3.1-ERP57 and ERP57 siRNA and treated with shikonin for 24 h.Cell lysates were prepared for the western blot analysis. (B) Non-transfected, pcDNA3.1-ERP57 and ERP57 siRNA transfected cells were treated with $2.5 \mu \mathrm{M}$ shikonin for $24 \mathrm{~h}$ and Annexin-V/PI staining was performed to measure apoptotic cells. (C) Percentage of apoptotic cells after treating non-transfected and transfected cells with shikonin for $24 \mathrm{~h}$.

therapeutic strategies, AML remains an incurable disease for majority of patients $[30,32$, 33]. Predominantly, development of chemoresistance is a major bottleneck limiting the therapeutic efficacy in AML therapy [34]. Natural products are important source of anticancer lead molecule and have shown a promising anticancerous activity against various cancers $[35,36]$. Shikonin is a natural product and it targets cancer cells through various mechanisms. For instance, shikonin inhibits cancer cell proliferation by targeting tumor specific pyruvate kinase-M2 (PKM2) [5]. Other mechanisms involve shikonin induced proteasome inhibition, NFkB inhibition, Thioredoxin reductase (TrxR1) inhibition [37-39]. In addition shikonin also sensitizes cancer cells towards chemotherapeutic drugs used for cancer therapy [40,41]. Our results showed that shikonin reduced the expression of ERstress proteins in AML cells which suggests that ER-stress promote AML cell survival.

Disturbance in the expression of ER-stress proteins has an important role in some human diseases, especially those involving tissues dedicated to extracellular protein synthesis [42].

Rapidly proliferating cancer cells need increased ER activity to assist the folding, assembly and transport of membrane and secretory proteins, and are thereby subjected to ER stress [43]. Because of insufficient vascularisation and rapid growth, tumor cells run into growth-limiting conditions such as hypoxia and nutrient deprivation [44]. An inadequate deliver of glucose affects protein glycosylation and the production of ATP, both of which could lead to the accumulation of unfolded proteins in the ER, resulting in ER stress [44]. Thus, in response to ER stress, activation of the UPR has been observed in various tumors [12]. In the case of leukemic cells, retroviral infection, the pathological expression of fusion protein PML-RAR $\alpha$ and the accumulation of reactive oxygen species (ROS) can all induce 


\section{Cellular Physiology Cell Physiol Biochem 2016;39:604-616 \begin{tabular}{l|l} 
DOI: 10.1159/000445652 & $\begin{array}{l}\text { O 2016 The Author(s). Published by S. Karger AG, Basel } \\
\text { www.karger.com/cpb }\end{array}$
\end{tabular} Trivedi et al.: ERP57 in AML Chemotherapy}

ER stress [45-47]. There is strong evidence for the role of UPR in the pathogenesis of many tumor types in humans particularly in rapidly growing solid tumors in which the demand for oxygen and nutrients can exceed the supply until new tumor-initiated blood vessels are formed [48]. In contrast, the role of the UPR during leukemogenesis remains largely unknown. As previous reports suggests that UPR is activated in a substantial subset of AML patients indicating a role of the UPR in the pathogenesis of these leukemias $[15,49]$. In our first step, we performed functional proteomics to screen potential mechanism and pathways involved in AML cell progression. Our results clearly showed that treatment of HL-60 cells with shikonin leads to sharp change in the proteins involved in proper folding of newly synthesized polypeptides (CALR, CCT5, ERP29, PPIA, PDIA3 (ERP57), HSPA5, and P4HB). Among all these proteins, ERP57 and Calreticulin were significantly downregulated by shikonin treatment.

ERP57 is a key member of the PDI family of proteins and it is mainly situated in the endoplasmic reticulum. It forms disulfide bonds and acts as a chaperone in nascent proteins $[9,10,50]$. However, reports on non-ER localizations of PDI family members identified PDI also in the cytosol and extracellular area suggesting additional roles for PDI. An interacting partner of ERP57, Calreticulin is another ER stress protein which has been reported to be expressed on leukemic blast cell surface in AML patients and its overexpression suppresses CEBPA protein translation thus blocking AML cell differentiation [51]. Recently, ERP57 has been reported to be a potential therapeutic target in renal fibrosis [27]. Our findings indicate that HL-60 and primary cells are found to overexpress ERP57 which was significantly downregulated by shikonin. We also showed that overexpression of ERP57 significantly reduces shikonin induced apoptosis in HL-60 while knocking down the expression of ERP57 leads to significant increase in shikonin induced apoptosis in HL-60 cells.

In conclusion, to the best of our knowledge, our study for the first time provided evidence that ERP57 is overexpressed in AML cells and is downregulated by shikonin. Shikonin may represent a potential therapeutic drug with promising antileukemic activity. A combination of shikonin with ERP57 inhibitor may further enhance its antileukemic effect.

\section{Disclosure Statement}

The authors declare that they have no competing interests.

\section{References}

1 Testa U, Riccioni R: Deregulation of apoptosis in acute myeloid leukemia. Haematologica 2007;92:81-94.

2 Ketley NJ, Allen PD, Kelsey SM, Newland AC: Mechanisms of resistance to apoptosis in human aml blasts: The role of differentiation-induced perturbations of cell-cycle checkpoints. Leukemia 2000;14:620-628.

3 Kulimova E, Oelmann E, Bisping G, Kienast J, Mesters RM, Schwable J, Hilberg F, Roth GJ, Munzert G, Stefanic M, Steffen B, Brandts C, Muller-Tidow C, Kolkmeyer A, Buchner T, Serve H, Berdel WE: Growth inhibition and induction of apoptosis in acute myeloid leukemia cells by new indolinone derivatives targeting fibroblast growth factor, platelet-derived growth factor, and vascular endothelial growth factor receptors. Mol Cancer Ther 2006;5:3105-3112.

4 Epple LM, Dodd RD, Merz AL, Dechkovskaia AM, Herring M, Winston BA, Lencioni AM, Russell RL, Madsen H, Nega M, Dusto NL, White J, Bigner DD, Nicchitta CV, Serkova NJ, Graner MW: Induction of the unfolded protein response drives enhanced metabolism and chemoresistance in glioma cells. PLoS One 2013;8:e73267.

5 Pyrko P, Schonthal AH, Hofman FM, Chen TC, Lee AS: The unfolded protein response regulator grp78/bip as a novel target for increasing chemosensitivity in malignant gliomas. Cancer Res 2007;67:9809-9816.

6 Sovolyova N, Healy S, Samali A, Logue SE: Stressed to death - mechanisms of er stress-induced cell death. Biol Chem 2014;395:1-13.

7 Lee AS: The glucose-regulated proteins: Stress induction and clinical applications. Trends Biochem Sci 2001;26:504-510. 


\section{Cellular Physiology Cell Physiol Biochem 2016;39:604-616 \begin{tabular}{l|l} 
DOI: 10.1159/000445652 & $\begin{array}{l}\text { O 2016 The Author(s). Published by S. Karger AG, Basel } \\
\text { www.karger.com/cpb }\end{array}$
\end{tabular} \\ Trivedi et al.: ERP57 in AML Chemotherapy}

8 Verfaillie T, Garg AD, Agostinis P: Targeting er stress induced apoptosis and inflammation in cancer. Cancer Lett 2013;332:249-264.

9 Di Jeso B, Park YN, Ulianich L, Treglia AS, Urbanas ML, High S, Arvan P: Mixed-disulfide folding intermediates between thyroglobulin and endoplasmic reticulum resident oxidoreductases erp57 and protein disulfide isomerase. Mol Cell Biol 2005;25:9793-9805.

10 Xu D, Perez RE, Rezaiekhaligh MH, Bourdi M, Truog WE: Knockdown of erp57 increases bip/grp78 induction and protects against hyperoxia and tunicamycin-induced apoptosis. Am J Physiol Lung Cell Mol Physiol 2009;297:L44-51.

11 Lai E, Teodoro T, Volchuk A: Endoplasmic reticulum stress: Signaling the unfolded protein response. Physiology (Bethesda) 2007;22:193-201.

12 Ma Y, Hendershot LM: Er chaperone functions during normal and stress conditions. J Chem Neuroanat 2004;28:51-65.

13 Tsai YC, Weissman AM: The unfolded protein response, degradation from endoplasmic reticulum and cancer. Genes Cancer 2010;1:764-778.

14 Lin JH, Li H, Yasumura D, Cohen HR, Zhang C, Panning B, Shokat KM, Lavail MM, Walter P: Ire1 signaling affects cell fate during the unfolded protein response. Science 2007;318:944-949.

15 Schroder M, Kaufman RJ: The mammalian unfolded protein response. Annu Rev Biochem 2005;74:739789.

16 Deng B, Feng Y: Tipe2 mediates the suppressive effects of shikonin on mmp13 in osteosarcoma cells. Cell Physiol Biochem 2015;37:2434-2443.

17 Gao D, Hiromura M, Yasui H, Sakurai H: Direct reaction between shikonin and thiols induces apoptosis in hl60 cells. Biol Pharm Bull 2002;25:827-832.

18 Wang X, Wang Y: Ginsenoside rh2 mitigates pediatric leukemia through suppression of bcl-2 in leukemia cells. Cell Physiol Biochem 2015;37:641-650.

19 Hsu PC, Huang YT, Tsai ML, Wang YJ, Lin JK, Pan MH: Induction of apoptosis by shikonin through coordinative modulation of the bcl-2 family, p27, and p53, release of cytochrome c, and sequential activation of caspases in human colorectal carcinoma cells. J Agric Food Chem 2004;52:6330-6337.

20 Yeh CC, Kuo HM, Li TM, Lin JP, Yu FS, Lu HF, Chung JG, Yang JS: Shikonin-induced apoptosis involves caspase-3 activity in a human bladder cancer cell line (t24). In Vivo 2007;21:1011-1019.

21 Mao X, Yu CR, Li WH, Li WX: Induction of apoptosis by shikonin through a ros/jnk-mediated process in bcr/ abl-positive chronic myelogenous leukemia (cml) cells. Cell Res 2008;18:879-888.

22 Singh F, Gao D, Lebwohl MG, Wei H: Shikonin modulates cell proliferation by inhibiting epidermal growth factor receptor signaling in human epidermoid carcinoma cells. Cancer Lett 2003;200:115-121.

23 Wang H, Wu C, Wan S, Zhang H, Zhou S, Liu G: Shikonin attenuates lung cancer cell adhesion to extracellular matrix and metastasis by inhibiting integrin beta1 expression and the erk1/2 signaling pathway. Toxicology 2013;308:104-112.

24 Gwon SY, Ahn JY, Jung CH, Moon BK, Ha TY: Shikonin suppresses erk 1/2 phosphorylation during the early stages of adipocyte differentiation in 3t3-11 cells. BMC Complement Altern Med 2013;13:207.

25 Hashimoto S, Xu M, Masuda Y, Aiuchi T, Nakajo S, Cao J, Miyakoshi M, Ida Y, Nakaya K: Betahydroxyisovalerylshikonin inhibits the cell growth of various cancer cell lines and induces apoptosis in leukemia hl-60 cells through a mechanism different from those of fas and etoposide. J Biochem 1999;125:17-23.

26 Han W, Li L, Qiu S, Lu Q, Pan Q, Gu Y, Luo J, Hu X: Shikonin circumvents cancer drug resistance by induction of a necroptotic death. Mol Cancer Ther 2007;6:1641-1649.

27 Dihazi H, Dihazi GH, Bibi A, Eltoweissy M, Mueller CA, Asif AR, Rubel D, Vasko R, Mueller GA: Secretion of erp57 is important for extracellular matrix accumulation and progression of renal fibrosis, and is an early sign of disease onset. J Cell Sci 2013;126:3649-3663.

28 Dihazi H, Dihazi GH, Jahn O, Meyer S, Nolte J, Asif AR, Mueller GA, Engel W: Multipotent adult germline stem cells and embryonic stem cells functional proteomics revealed an important role of eukaryotic initiation factor 5a (eif5a) in stem cell differentiation. J Proteome Res 2011;10:1962-1973.

29 Agarwal NK, Mueller GA, Mueller C, Streich JH, Asif AR, Dihazi H: Expression proteomics of acute promyelocytic leukaemia cells treated with methotrexate. Biochim Biophys Acta 2010;1804:918-928.

30 Lovat PE, Corazzari M, Armstrong JL, Martin S, Pagliarini V, Hill D, Brown AM, Piacentini M, Birch-Machin MA, Redfern CP: Increasing melanoma cell death using inhibitors of protein disulfide isomerases to 


\section{Cellular Physiology Cell Physiol Biochem 2016;39:604-616 \begin{tabular}{l|l} 
DOI: 10.1159/000445652 & $\begin{array}{l}\text { O 2016 The Author(s). Published by S. Karger AG, Basel } \\
\text { www.karger.com/cpb }\end{array}$
\end{tabular} \\ Trivedi et al.: ERP57 in AML Chemotherapy}

abrogate survival responses to endoplasmic reticulum stress. Cancer Res 2008;68:5363-5369.

31 Kang SH, Jeong SJ, Kim SH, Kim JH, Jung JH, Koh W, Kim DK, Chen CY: Icariside ii induces apoptosis in u937 acute myeloid leukemia cells: Role of inactivation of stat3-related signaling. PLoS One 2012;7:e28706.

32 Adamia S, Haibe-Kains B, Pilarski PM, Bar-Natan M, Pevzner S, Avet-Loiseau H, Lode L, Verselis S, Fox EA, Burke J, Galinsky I, Dagogo-Jack I, Wadleigh M, Steensma DP, Motyckova G, Deangelo DJ, Quackenbush J, Stone R, Griffin JD: A genome-wide aberrant rna splicing in patients with acute myeloid leukemia identifies novel potential disease markers and therapeutic targets. Clin Cancer Res 2014;20:1135-1145.

33 Zhang R, Yang W, Li YC, Zhang GJ, Yao K, Hu R, Wu B: The opn gene polymorphism confers the susceptibility and response to ara-c based chemotherapy in chinese aml patients. Cell Physiol Biochem 2015;35:175-183.

34 Liu L, Herfindal L, Jokela J, Shishido TK, Wahlsten M, Doskeland SO, Sivonen K: Cyanobacteria from terrestrial and marine sources contain apoptogens able to overcome chemoresistance in acute myeloid leukemia cells. Mar Drugs 2014;12:2036-2053.

35 Mondal S, Bandyopadhyay S, Ghosh MK, Mukhopadhyay S, Roy S, Mandal C: Natural products: Promising resources for cancer drug discovery. Anticancer Agents Med Chem 2012;12:49-75.

36 Fulda S: Modulation of apoptosis by natural products for cancer therapy. Planta Med 2010;76:1075-1079.

37 Wang Y, Zhou Y, Jia G, Han B, Liu J, Teng Y, Lv J, Song Z, Li Y, Ji L, Pan S, Jiang H, Sun B: Shikonin suppresses tumor growth and synergizes with gemcitabine in a pancreatic cancer xenograft model: Involvement of nfkappab signaling pathway. Biochem Pharmacol 2014;88:322-333.

38 Duan D, Zhang B, Yao J, Liu Y, Fang J: Shikonin targets cytosolic thioredoxin reductase to induce rosmediated apoptosis in human promyelocytic leukemia hl-60 cells. Free Radic Biol Med 2014;70:182-193.

39 Yang H, Zhou P, Huang H, Chen D, Ma N, Cui QC, Shen S, Dong W, Zhang X, Lian W, Wang X, Dou QP, Liu J: Shikonin exerts antitumor activity via proteasome inhibition and cell death induction in vitro and in vivo. Int J Cancer 2009;124:2450-2459.

40 Li W, Liu J, Jackson K, Shi R, Zhao Y: Sensitizing the therapeutic efficacy of taxol with shikonin in human breast cancer cells. PLoS One 2014;9:e94079.

41 Wu X, Yang N, Zhou WH, Xu J, Chen JJ, Zheng FM, Long ZJ, Yue CF, Ai KX, Liu LL, Wan XY, Liu Q: Up-regulation of p21 inhibits trail-mediated extrinsic apoptosis, contributing resistance to saha in acute myeloid leukemia cells. Cell Physiol Biochem 2015;34:506-518.

42 Oyadomari S, Mori M: Roles of chop/gadd153 in endoplasmic reticulum stress. Cell Death Differ 2004;11:381-389.

43 Wang G, Yang ZQ Zhang K: Endoplasmic reticulum stress response in cancer: Molecular mechanism and therapeutic potential. Am J Transl Res 2010;2:65-74.

44 Luo B, Lee AS: The critical roles of endoplasmic reticulum chaperones and unfolded protein response in tumorigenesis and anticancer therapies. Oncogene 2013;32:805-818.

45 Zhang Y, Soboloff J, Zhu Z, Berger SA: Inhibition of ca2+ influx is required for mitochondrial reactive oxygen species-induced endoplasmic reticulum ca2+ depletion and cell death in leukemia cells. Mol Pharmacol 2006;70:1424-1434.

46 Khan MM, Nomura T, Chiba T, Tanaka K, Yoshida H, Mori K, Ishii S: The fusion oncoprotein pmlraralpha induces endoplasmic reticulum (er)-associated degradation of n-cor and er stress. J Biol Chem 2004;279:11814-11824.

47 Saleh AM, Aljada A, El-Abadelah MM, Sabri SS, Zahra JA, Nasr A, Aziz MA: The pyridone-annelated isoindigo (5'-cl) induces apoptosis, dysregulation of mitochondria and formation of ros in leukemic hl-60 cells. Cell Physiol Biochem 2015;35:1958-1974.

48 Schardt JA, Mueller BU, Pabst T: Activation of the unfolded protein response in human acute myeloid leukemia. Methods Enzymol 2011;489:227-243.

49 Schardt JA, Weber D, Eyholzer M, Mueller BU, Pabst T: Activation of the unfolded protein response is associated with favorable prognosis in acute myeloid leukemia. Clin Cancer Res 2009;15:3834-3841.

50 Bourdi M, Demady D, Martin JL, Jabbour SK, Martin BM, George JW, Pohl LR: Cdna cloning and baculovirus expression of the human liver endoplasmic reticulum p58: Characterization as a protein disulfide isomerase isoform, but not as a protease or a carnitine acyltransferase. Arch Biochem Biophys 1995;323:397-403.

51 Schardt JA, Mueller BU, Pabst T: Activation of the unfolded protein response in human acute myeloid leukemia. Methods Enzymol 2010;489:227-243. 